\title{
Numerical Assessment of Data in Catalytic and Transitional Flows for Martian Entry
}

\author{
Matthew MacLean ${ }^{*}$ and Michael Holden ${ }^{\dagger}$ \\ CUBRC, Aerothermal/Aero-optics Evaluation Center, Buffalo, NY, 14225
}

\begin{abstract}
The conditions for a typical run from the MSL phase two study of transition that was performed in the LENS facility have been analyzed to understand the sensitivity to the freestream conditions of the facility. A simplified analysis technique has been used based on energy accounting to freeze specified portions of the chemical or vibrational energy during the expansion process in the nozzle. The effect of freezing this energy results in increased shock standoff distance that better matches the measured shock shape. Based on several cases, it was found that freezing approximately $42 \%$ of the total enthalpy of the flow in the vibration mode results in the best agreement with the measured shock shape. This modified condition also results in significantly better agreement with the measured surface heat transfer at the stagnation point and with the measured pressure at the shoulders of the model. Based on this adjusted freestream condition, the surface heat transfer data shows behavior generally consistent with fully-catalytic recombination on the cold wall. This behavior is consistent with previous results obtained in shock tunnel facilities in carbon dioxide, air, and nitrogen. Although the mechanism causing this frozen energy in the flow has not been identified, the sensitivity of the transition onset point of the flowfield to this phenomenon has been estimated to be less than $10 \%$ based on a simple transition criterion.
\end{abstract}

\section{Introduction}

$\mathrm{R}$ eliable payload delivery systems are necessary to deliver lander and rover payloads to other planets in the solar system in order to fulfill NASA's current planetary exploration directive, a primary focus of which is Mars. Although the costs and limited launch opportunities of such exploratory programs require that the re-entry vehicle have a high factor of safety to insure good odds of success, an overly conservative design will result in reduced payload capacity and, hence, reduced scientific opportunity for the mission. Because the opportunities for flight tests in the Martian atmosphere are rare and the ability to collect data from such an experiment is typically limited or impossible, the optimization of heat shield design to insure robustness while minimizing unnecessary conservatism must be carried out in ground test facilities here on Earth.

The Mars Science Laboratory (MSL) mission is the next scheduled NASA rover vehicle targeting the exploration of the Martian surface that will depart from Earth. As part of the aerothermal environment specification, a two phase program has been completed at CUBRC to measure the effects of flow transition on the forebody design of the entry, descent, and landing (EDL) shape. Although the $70^{\circ}$ sphere-cone aeroshell geometry is quite similar to previous missions to Mars such as Viking, Pathfinder, and the Mars Exploration Rovers (MER), the MSL design will be considerably larger than any previous EDL configuration. The increased size results in trajectories which will be more significantly dominated by turbulent heating than in any previous mission. This augmented heating environment requires additional understanding of the physics involved to accurately design the vehicle.

In phase one of this program, CUBRC tested a $61 \mathrm{~cm}$ (24") diameter sphere-cone model in the LENS-I facility over a wide range of Reynolds numbers at effective flow enthalpies of 5 and $10 \mathrm{MJ} / \mathrm{kg}$. The model was constructed of stainless steel and coated with magnesium-fluoride. The instrumentation package consisted of a ray of thin-film heat transfer gages on the centerline of the model running from the windward corner to the leeward corner. Additional angular rays of gages were located on the leeward side of the model at three constant radius locations. This primary instrumentation was supplemented with several forebody pressure gages, several forebody

\footnotetext{
* Senior Research Scientist, AIAA Member.

${ }^{\dagger}$ AAEC Program Manager, AIAA Fellow.

Copyright (C2006 by Matthew MacLean. Published by the American Institute of Aeronautics and Astronautics, Inc. (AIAA) with permission.
} 
coaxial thermocouple heat transfer gages, and a few thin-film gages on the backside of the model to assess wake establishment. Laminar, transitional, and turbulent heating data was acquired at angles of attack of $16^{\mathrm{O}}, 11^{\mathrm{O}}$ (the nominal flight angle), and $0^{\mathrm{O}}$. The details of the phase one study and the post-test data analysis are given by MacLean, et $\mathrm{al}^{1}$. and Hollis, et $\mathrm{al}^{2}$.

The results of the phase one study showed that we did not acquire data for a fully laminar baseline case at angle of attack because of the large size of the model. Also, surface catalysis was found to be a central problem in the ground test studies. In studies in both LENS and the Caltech $\mathrm{T} 5$ facility $^{3}$, measured surface heating for laminar flows always showed a level that was consistent with predictions for fully-catalytic recombination to pure carbon dioxide at the cold wall. The phase two study tested a 31cm (12") sphere-cone model, or half the size of the original model. The smaller size was designed to better target laminar flow conditions at angle of attack to compliment and verify the phase one results. To investigate the catalytic heating effect, the phase two model employed three distinct types of instrumentation. First, coaxial type thermocouple gages were installed on the windward and leeward centerline of the model, forming a continuous metallic surface exposed to the flow. Second, thin-film gages were employed on a continuous strip of pyrex, eliminating the discontinuity of alternating metallic/non-metallic surfaces that the flow was exposed to in phase one. Third, silver calorimeter gages were installed in the model, as silver is known to be a catalytic material to many reactions.

In our efforts to measure transitional and turbulent heating on these bodies in a high enthalpy carbon dioxide flow, we have found that the understanding of this data is a highly coupled process. In order to understand the transitional heating on the surface, one must understand the surface catalysis of the steel ground test models. In order to understand the catalytic response of the model, one must understand the thermodynamic and chemical state of the gas on the freestream and the shock layer of the flowfield. Thus, these effects must be considered in this order to make a correct estimate of the data.

In the phase two results, our measurements of shock shape deviates from the shape predicted by CFD when computed with a nominal set of freestream conditions. These freestream conditions are found for each run by computing the nozzle flowfield from reservoir to test section with a single degree of freedom simple harmonic oscillator using rates from Camac and appropriate chemistry reaction rates evaluated using a $T$-TV dissociation coupling model. This model predicts that the vibrational degree of freedom is approximately in equilibrium with the translation-rotation temperature for the range of densities that we studied. In each case, the bow shock that was measured from Schlieren photography shows a larger stand-off distance than the prediction. Further study of these conditions suggests that there is a larger frozen energy component in the freestream of the facility than the current modeling methodology predicts.

\section{Experimental Facility Background}

Currently, CUBRC operates the 48" reflected shock tunnel, the LENS-I and LENS-II reflected shock tunnels", and the LENS-X expansion tunnel ${ }^{5}$. The reflected shock tunnel uses a shock to heat and pressurize a stagnant test gas to high enthalpy levels. This test gas may then be expanded through a converging-diverging nozzle in a manner similar to a blowdown facility to produce a hypervelocity test flow. Expansion tunnels like LENS-X also operate as short duration facilities, but an expansion tunnel produces a high enthalpy flow without the need to first stagnate the test gas. In an expansion tunnel, the high enthalpy gas is generated in two stages. In the first stage, the test gas in the driven tube is compressed and heated by a shock, but the moving flow behind the incident shock is not immediately brought to a halt by a reflected shock as in a reflected shock tunnel. Secondly, additional energy is

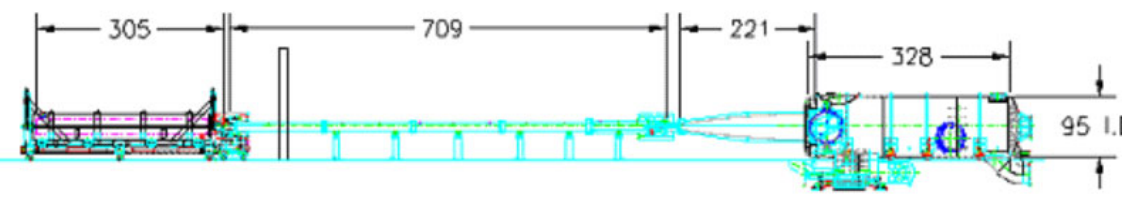

(a) LENS-I Facility

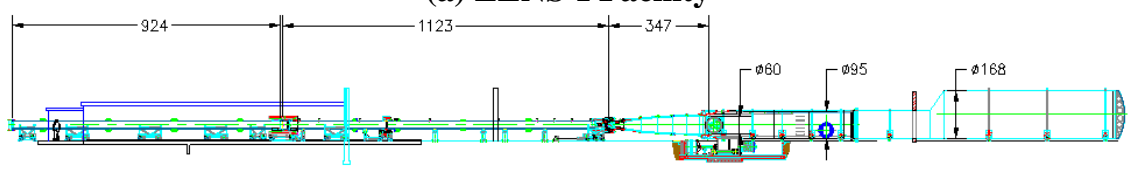

(b) LENS-II Facility

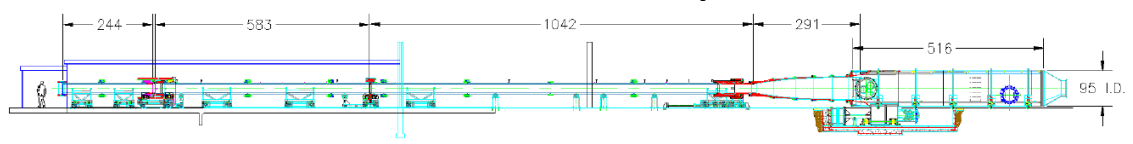

(c) LENS-X Facility

Figure 1. Drawings of CUBRC LENS Hypervelocity Shock Tunnel Facilities with Nominal Dimensions [all values shown in inches]. 
added to this moving gas by an unsteady expansion in the acceleration segment of the tunnel to produce a low static temperature, high velocity test gas which is then isentropically expanded in a diverging nozzle to achieve a high enthalpy test flow at a thermodynamic state like that of a flight condition. The result is a freestream flow that is free of frozen, dissociated chemical contamination that can plague reflected shock facilities at enthalpies exceeding 10 $\mathrm{MJ} / \mathrm{kg}$. While the useable test times from an expansion tunnel are generally shorter than those from a reflected shock tunnel, the clean, very high enthalpy flows that an expansion tunnel can generate provides a unique testing capability. A schematic of all of the LENS facilities with basic length scales is given in Fig. 1.

The LENS reflected shock-tunnel facilities were developed primarily to study the full-scale, hypervelocity flow physics of interceptors and air-breathing engine configurations. The scale and flow duplication capabilities of LENS are such that these vehicles can be studied at their full scale, inclusive of effects such as transition to turbulence, turbulent mixing from cross-flow jets and thrusters, duplicated flow chemistry and other effects that are difficult or impossible to simulate at cold-flow or sub-scale conditions. Besides aerothermal measurements, extensive studies in this facility have been made using non-intrusive diagnostics such as aero-optic and aero-acoustic measurements, including recent work with tunable laser-diode diagnostics ${ }^{6}$. The capabilities of LENS-I duplicate the flight conditions of interceptors and scramjet engines from Mach 7 to 15 (with Reynolds number matching to Mach 22), while the LENS-II facility complements it in such a way that this capability is seamlessly extended down to Mach 3.5 at sea level density.

Although any of the three LENS facilities or the 48" tunnel can use carbon dioxide test gas with no special effort to set up, LENS-I was used for all tests to date because it is most compatible with the primary goal of obtaining transition data on a $70^{\circ}$ sphere-cone model for the MSL program. The capability to use heated hydrogen for a driver gas in LENS-I provided transition data at the most relevant enthalpy for the Martian entry trajectory. The contoured D nozzle using some of the existing throats in LENS-I was found to produce reasonably uniform exit profiles in carbon dioxide without any modification, despite the fact that the expansion of carbon dioxide into the test section produces a lower Mach number than the same nozzle does for air at the same enthalpy. Sample results demonstrating the uniformity of the test core in carbon dioxide have already been shown ${ }^{1,7}$ and will not be repeated here. A typical capability map of density versus velocity is shown in Fig. 2 for carbon dioxide showing the three LENS facilities. The potential range of conditions, particularly for LENS-II and LENS-X, has been assessed analytically because the range of calibrated conditions are currently limited. A velocityaltitude graph for the Martian atmosphere was initially considered but was found to be uninteresting as the Martian atmosphere is so thin that all three facilities are capable of producing significantly higher than surface level densities. A typical entry trajectory is also shown from the Pathfinder mission ${ }^{8}$. The density of the trajectory has been increased to maintain a $(\rho L)$ simulation on a model scale that can fit conveniently in all three facilities, and the resulting trajectory has been found to fit well in the LENS capability range.

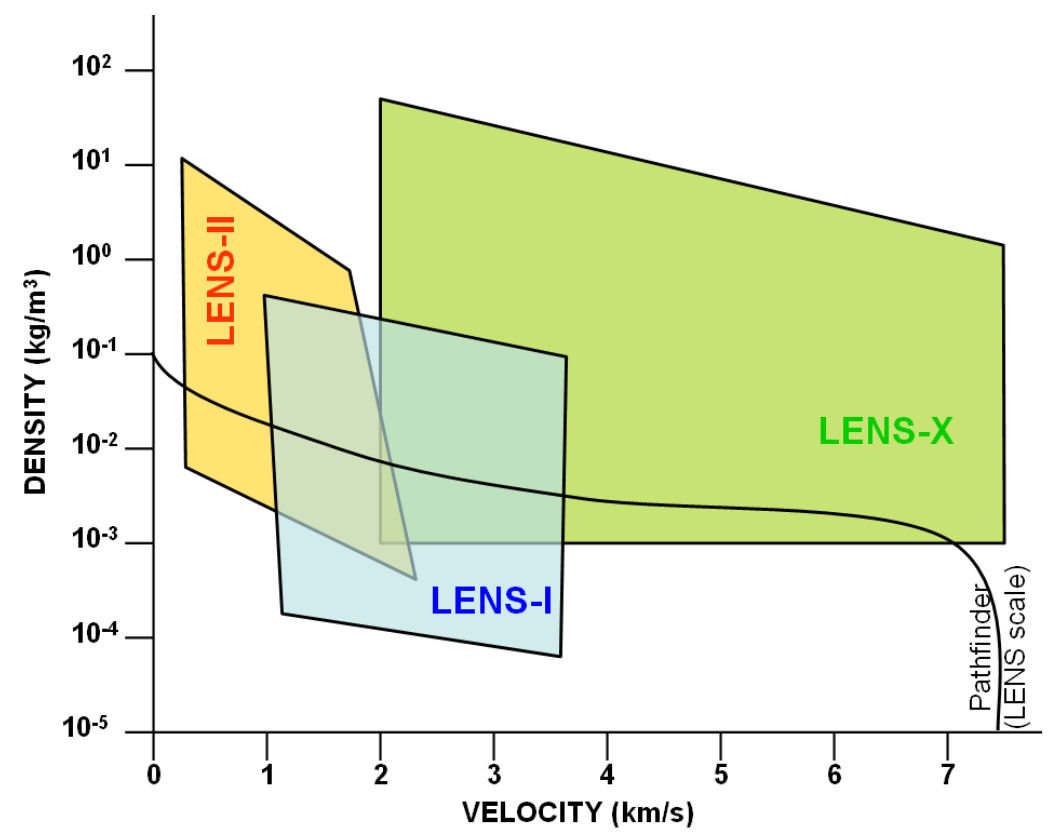

Figure 2. Density-Velocity Map of the CUBRC Facilities using Carbon Dioxide Test Gas

\section{Supporting Numerical}

\section{Tools}

\section{A. DPLR Code}

All ground test studies in the LENS facilities are extensively calibrated and validated with numerical tools. The primary CFD tool used in these efforts is the DPLR code provided by NASA Ames Research Center. DPLR is 
a multi-block, structured, finite-volume code that solves the reacting Navier-Stokes equations including finite rate chemistry and finite rate vibrational non-equilibrium effects. This code is based on the data-parallel line relaxation method $^{9}$ and implements a modified (low dissipation) Steger-Warming flux splitting approach ${ }^{10}$ for the convection terms and central differencing for the diffusion terms. Finite rate vibrational relaxation is modeled via one simple harmonic oscillator vibrational degree of freedom ${ }^{11}$ using the Landau-Teller model ${ }^{12}$. Vibrational energy relaxation rates are computed by default from the semi-empirical expression due to Millikan and White ${ }^{13}$, but rates from the work of Camac ${ }^{14}$ are substituted for the $\mathrm{CO}_{2}-\mathrm{CO}_{2}$ collisions and those collected by Park, et $\mathrm{al}^{15}$. for the other collisions in the cases studied here. Vibration-dissociation coupling is currently modeled using the $T$ - $T v$ approach of Park ${ }^{16}$ with an exponent on both temperatures of 0.50. Transport properties are appropriately modeled in DPLR for this type of flow ${ }^{17,18}$ using the binary collision-integral based mixing rules from Gupta, et al $^{19}$. Diffusion coefficients are modeled using the self-consistent effective binary diffusion (SCEBD) method ${ }^{20}$. Turbulence models available in the DPLR code currently include the Baldwin-Lomax 0-equation model ${ }^{21}$, the Spalart-Allmaras model 1-equation model $^{22}$, and the Shear Stress Transport (SST) 2-equation model ${ }^{23}$ each with corrections for compressibility effects ${ }^{24,25}$.

The issue of the chemical wall boundary condition deserves some specific consideration and DPLR is programmed with several options. The non-catalytic wall boundary condition provides the lowest level of surface heating. The super-catalytic boundary condition provides the highest possible level of heating because the mixture is returned to its lowest possible chemical energy state at the wall, meaning that the maximum amount of chemical energy has been distributed to the other energy modes. In this case, that state corresponds to $100 \% \mathrm{CO}_{2}$. The supercatalytic boundary is non-physical in that it does not identify a specific mechanism by which the recombination occurs, but assumes that it has occurred by some unidentified process without consideration of rate mechanisms. In the case of short-duration facilities like LENS, the surface temperature of the model never rises appreciably above room temperature, so the super-catalytic $\mathrm{CO}_{2}$ condition corresponds to a fully-accommodated chemical state.

\section{B. CREST Code}

The LENS facilities are typically operated using a tailored interface, meaning that the interface between the driver and the test gas is brought exactly to a halt by the reflected shock off the endwall. This results in the maximum of test time for the facility as the test period ends when expansion waves from the driver arrive at the endwall. For a large scale facility operating using a tailored interface, the state of the reservoir gas may be computed assuming a single incident shock into the test gas followed by a single reflected shock. The state of the gas behind these two shocks is that of the reservoir.

The reservoir conditions for each run are computed from measured values of shock speed and the initial temperature and pressure in the driven tube. The CUBRC Reservoir Equilibrium Shock Tunnel (CREST) code has been developed to compute the properties behind each moving shock ${ }^{26}$. Downstream of both the incident and the reflected shock, equilibrium chemistry and thermodynamics are assumed. Equilibrium contributions of vibrational and/or electronic energy excitation are included in the state calculation, and the equilibrium concentrations of all included species are also solved for. Further, because the LENS-I facility can generate dense reservoir states in excess of 100 times sea level density, the excluded volume equation of state as discussed by Lordi and Mates ${ }^{27}$ is employed. In the excluded volume approach, the ideal-gas law is modified to include a term that accounts for the effective volume taken up by the gas molecules. Thus, at low densities, this term becomes insignificant, and results consistent with the ideal-gas law are returned. Because of the equilibrium calculation, the downstream properties of each shock must be found with a non-linear, iterative solver. The measured reservoir pressure during the run is used to correct the computed reservoir state of the gas, which accounts for effective area change in the endwall region of the facility resulting from our centerbody valve system that protects the test articles and instrumentation from excessive particulate damage after each run.

In the case of carbon dioxide tests, a four species model that includes $\mathrm{CO}_{2}, \mathrm{CO}, \mathrm{O}_{2}$, and $\mathrm{O}$ is used. Initially, $\mathrm{C}$ was also included but was found to be negligible at the conditions for the LENS facilities. The results from CREST have been found to agree with the results from both the ESTC ${ }^{28}$ and CEA ${ }^{29}$ codes for low density cases where the non-ideal gas effects are not important. CEA, which includes contributions from several dozen species, shows that only the four included species are present for our range of conditions in any significant concentration.

\section{Nozzle Code}

A specialized code has been developed by Candler $^{30}$ to compute the nozzle flowfield for a high-pressure, high-enthalpy ground test facility. This code shares much of its heritage with the NASA Ames DPLR code (described in A above) as it employs the same flux splitting and time integration treatments. The nozzle code has been streamlined by hardwiring parts of the code to solve for a single-block, axisymmetric nozzle with fixed 
boundary conditions. These modifications lead to a substantial decrease in required solution time and allow us to compute the nozzle flowfield in the same length of time that it requires to set-up and make a run in the LENS facilities (about 2 hours).

The nozzle code employs the Spalart-Allmaras ${ }^{22}$ one-equation turbulence model with the Catris and Aupoix compressibility correction ${ }^{25}$. This turbulence formulation has been shown to adequately predict the displacement of the turbulent boundary layer in the throat region of the nozzle and subsequent boundary layer distortion caused by the rapid reduction in local Reynolds number in the diverging section of the nozzle. We have demonstrated this agreement through comparisons with measured Pitot pressure profiles in the freestream in several previous publications ${ }^{7,30}$.

The nozzle code also uses the same excluded volume equation of state as does the CREST code, so that results from CREST become consistent input boundary conditions to the subsonic inflow plane. Computed freestream conditions from the nozzle code are also consistent with the model flowfield calculations done with DPLR since both codes employ the same thermo-chemical models, constants, and rate coefficients. Thus, without the excluded volume correction, we would expect the nozzle code and DPLR to produce the same result for the nozzle flowfield.

\section{Analysis of Flow Conditions with Carbon Dioxide Test gas}

\section{A. Nominal Conditions on the Model}

Because of the large negative heat of formation of carbon dioxide, the definition of total enthalpy in the flow can be somewhat misleading. Thus, the convention defined by Eqn (1) is used throughout this publication. The effective total enthalpy provided by the shock tunnel is the net increase in energy from the initial

Table 1. Reservoir Conditions for Run 8

\begin{tabular}{|c|c|c|c|}
\hline $\mathrm{P}_{0}$ & $29.5 \mathrm{MPa}$ & $\rho$ & $38.30 \mathrm{~kg} / \mathrm{m}^{3}$ \\
\hline $\mathrm{T}_{0}=\mathrm{T}_{\mathrm{V} 0}$ & $3,499 \mathrm{~K}$ & $\mathrm{c}_{\mathrm{CO} 2}$ & 0.7701 \\
\hline $\mathrm{h}_{0} \mathrm{EFF}$ & $5.63 \mathrm{MJ} / \mathrm{kg}$ & $\mathrm{c}_{\mathrm{CO}}$ & 0.1463 \\
\hline $\mathrm{h}_{0}$ & $-3.09 \mathrm{MJ} / \mathrm{kg}$ & $\mathrm{C}_{\mathrm{O} 2}$ & 0.0798 \\
\hline $\mathrm{h}_{\text {INITIAL }}$ & $-8.72 \mathrm{MJ} / \mathrm{kg}$ & $\mathrm{c}_{\mathrm{O}}$ & 0.0037 \\
\hline
\end{tabular}
state in the driven tube, which is defined as $100 \%$ carbon dioxide at the measured wall temperature and driven tube pressure in the lab. This convention insures that total enthalpy will always be a positive number, making it more consistent with the expected results when one is testing in air or nitrogen. Also, since the reflected shock tunnel facility does not see a significant increase in wall temperature during the run time, the term given in Eqn (1) is useful and relevant in the aerothermal analysis to, for example, define the Stanton number.

$$
h_{0}^{E F F}=h_{0}-h_{\text {INITIAL }}
$$

As a typical, representative case, run 8 from the MSL phase-two program has been selected for further study. This run measured the phase-two sphere-cone heating at zero degrees angle of attack (an axisymmetric flowfield) at a relatively low total pressure and freestream unit Reynolds number to obtain fully laminar flow on the body. The total enthalpy effective increase for this case was 5.63 $\mathrm{MJ} / \mathrm{kg}$. The complete set of equilibrium reservoir conditions as computed by the CREST code is given in Table 1.

Calculations were performed with the nozzle code tool to determine the freestream conditions for all runs. A single set of values was used from the centerline of each calculation at the axial station in the test section where the nose of the model was positioned. The degree of non-uniformity in the test section of the facility is small enough that it is not expected to be significant for this body shape. In the nominal case, the vibration is treated with the Landau-Teller model with a common vibrational temperature using Camac rates. The result of this

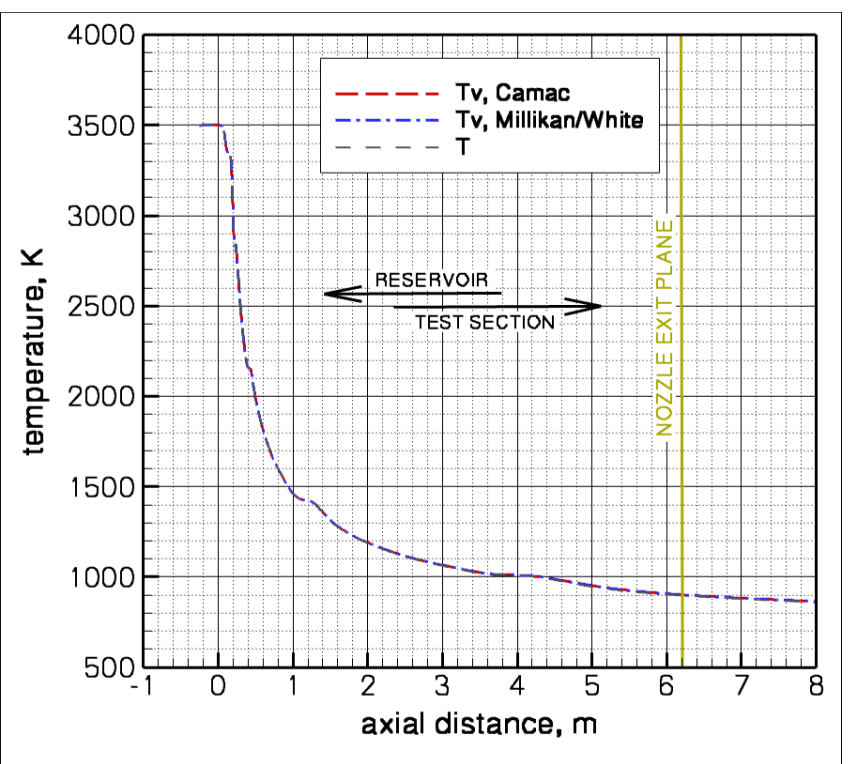

Figure 3. Prediction of Vibrational Relaxation of $\mathrm{CO}_{2}$ Gas in LENS Nozzle with Camac and Millikan-White Rates 
calculation shows that the vibration is closely in equilibrium with the translation-rotation temperature. However, the rates of Camac were measured for relaxation behind a shock and are known to be very fast. The slower rates computed from the Millikan-White relation were also employed in an alternate calculation. Despite the larger vibrational time constant of the Millikan-White formulation, equilibrium vibration is still predicted in the freestream. Figure 3 shows the computed centerline vibrational temperature for both the Camac case and the Millikan-White case with the translational temperature included for reference as a function of axial station down the nozzle. The exit plane of the nozzle is indicated, and the model was tested just beyond the exit plane. The computed set of freestream conditions are given
Table 2. Nominal Prediction of Freestream Conditions for Run 8 using Nozzle Code

\begin{tabular}{|c|c|}
\hline $\mathrm{U}[\mathrm{m} / \mathrm{s}]$ & 2,871 \\
\hline $\mathrm{P}[\mathrm{Pa}]$ & 1,613 \\
\hline $\mathrm{T}[\mathrm{K}]$ & 892 \\
\hline $\mathrm{T}_{\mathrm{V}}[\mathrm{K}]$ & 896 \\
\hline$\rho\left[\mathrm{kg} / \mathrm{m}^{3}\right]$ & $8.96 \times 10^{-3}$ \\
\hline $\mathrm{M}_{\mathrm{FROZEN}}$ & 5.72 \\
\hline $\mathrm{c}_{\mathrm{CO} 2}$ & 0.8630 \\
\hline $\mathrm{C}_{\mathrm{CO}}$ & 0.0872 \\
\hline $\mathrm{C}_{\mathrm{O} 2}$ & 0.0497 \\
\hline $\mathrm{C}_{\mathrm{O}}$ & 0.0000 \\
\hline
\end{tabular}

in Table 2. As both sets of vibrational rates produced the same solution, a single set of freestream conditions is given. For this freestream model, the vibration has equilibrated, and a large percentage of the chemical energy has been reclaimed. Also, the remaining oxygen is in the form of molecular oxygen and there is not a significant percentage of atomic oxygen present. This has been a typical finding in both the LENS and $\mathrm{T} 5$ tests. The Mach number is the frozen Mach number for the flow with vibrational nonequilibrium to facilitate a consistent definition with cases considered in the next section.

When these freestream conditions are used to compute the sphere-cone flowfield with the DPLR code using the same chemical kinetic and vibrational rate models, the surface heating and pressure predictions show reasonable overall agreement with the data. The comparison with the pressure measurements is shown in Fig. 4, where the experimental data points have been reflected across the centerline because the flow is symmetric. The Pitot pressure at the nose is wellpredicted by the CFD and the decreasing trend down the conic frustrum seems to be generally captured by the CFD.

The comparison of heat transfer is shown in Fig. 5. Here, the comparison is more interesting. As we have shown in previous results for both $\mathrm{CO}_{2}$ and air ${ }^{1,31}$, the surface heat transfer measurements compare very well with fully catalytic recombination at the wall for this enthalpy level. This trend is observed for this run also. The fully-catalytic prediction along the conical surface captures the data well, while the non-catalytic wall clearly under-predicts the heating. The only noticeable exceptions to this conclusion are the three gages at and on either side of the stagnation point. Here, the measured heating data dips significantly below the prediction. While accurate CFD prediction of

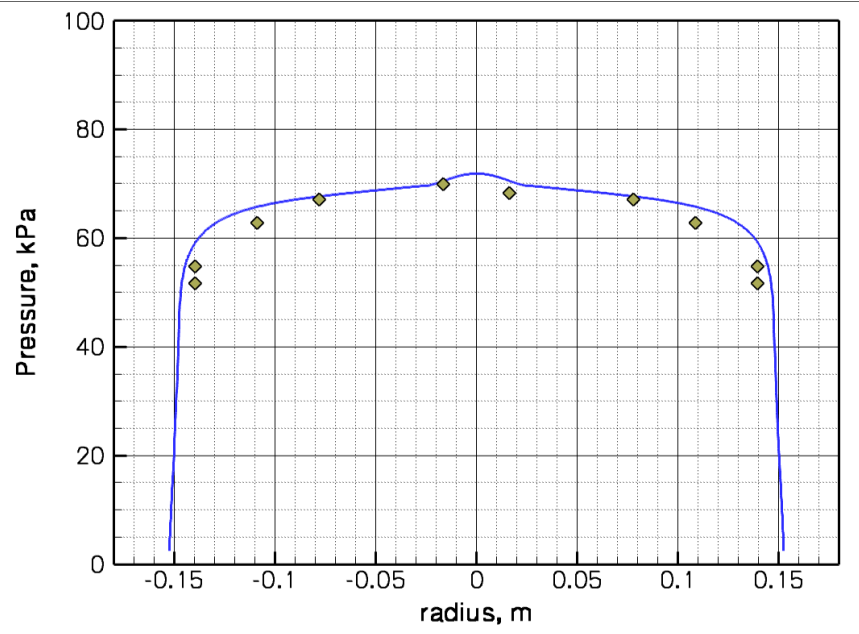

Figure 4. Comparison of DPLR Prediction of Surface Pressure for Run 8 using the Nominal Conditions in Table 2

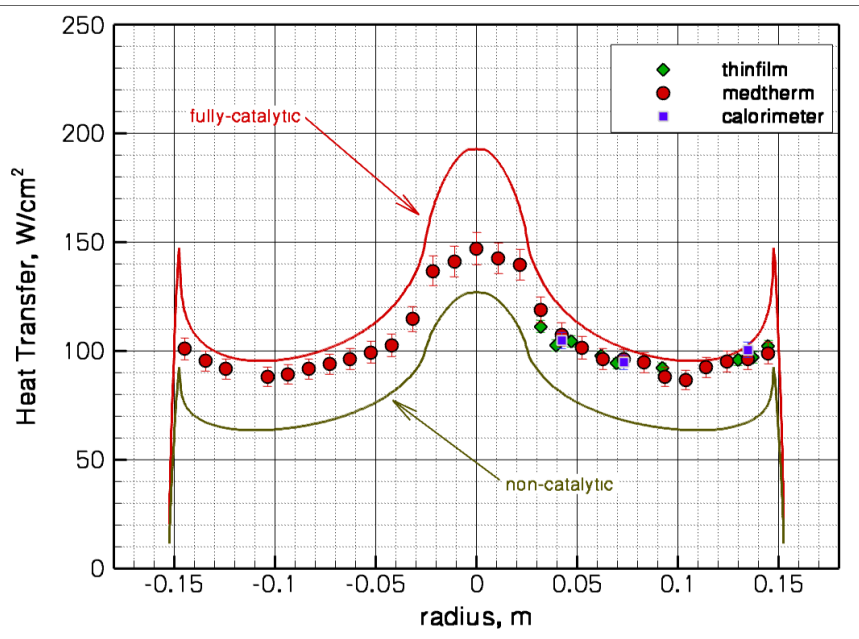

Figure 5. Comparison of DPLR Prediction of Surface Heat Transfer for Run 8 using the Nominal Conditions in Table 2 
heat transfer is difficult at the stagnation point because of the sensitivity to eigenvalue computation for misaligned grids, the grid has been carefully aligned to the bow shock to insure an accurate computation of heat transfer. Initially, it was assumed that this discrepancy in observed heat transfer was due to a limiting reaction in the surface catalysis recombination near the stagnation point. We will show in the next section that there is another reason for this discrepancy with the data.

Finally, although the comparison of predicted and measured surface data seems in reasonable overall agreement with this case for both pressure and heat transfer, we found that the computed shock shape is significantly different than the measured shock shape using a single-pass Schlieren technique. This discrepancy is shown in Fig. 6. The shocks are clearly very different in shape, with the measured stand-off distance at the nose equal to 2.25 times the computed stand-off distance for this case.

The fact that the shock shape does not match is at first troubling. Driver gas contamination was initially suspected for this result, but several facts seem to indicate that is not the cause of the issue. First, a later run in this test program was made with an equal mixture of helium and hydrogen driver gas. The conditions were found to be very close to those produced in run 8 , and both runs produced a similar shock shape and heating profile. Thus, the change of driver gas does not seem to influence the results. Further, LENS is routinely used to test in air and nitrogen in excess of $10 \mathrm{MJ} / \mathrm{kg}$ and we have not seen any evidence of this increased stand-off behavior in any of those tests. We can think of no reason why the driver gas would be any more influential in carbon dioxide than in other gases. Thus, evidence suggests that the anomalous shock stand-off is caused by the thermodynamics of the carbon

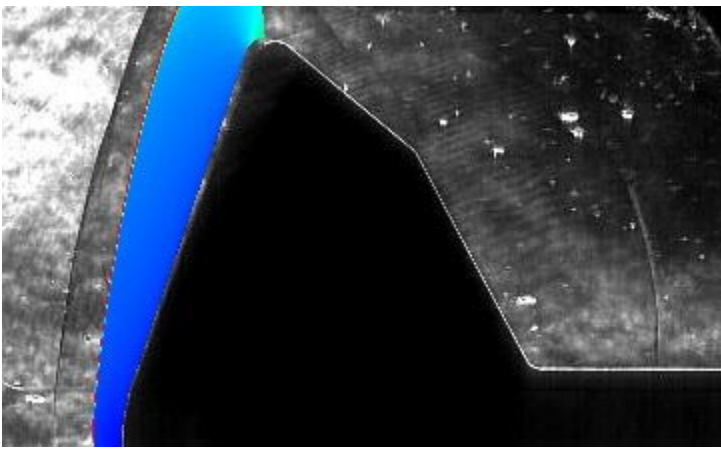

Figure 6. Comparison of Measured and Computed Shock Shape for Run 8 using the Nominal Conditions in Table 2 dioxide mixture during the expansion process in the nozzle.

\section{B. Analysis of Sensitivity to Frozen Energy}

Figure 7 shows the detailed breakdown of the energy modes in the reservoir of the facility for this run. In the reservoir, the gas is stagnant so kinetic energy of the flow is zero. The remainder of the flow is in equilibrium chemically and thermodynamically. In each category, the percent of energy has been defined consistently as the energy increase in that category divided by the total enthalpy increase, defined in Eqn (1). For example, the percent of translational energy increase is the difference between the translational energy in the reservoir and the translational energy in the initial driven-tube state then divided by the total enthalpy increase. As a percentage, this term is $18.2 \%$ of the total. The vibrational mode, which contributes $30.2 \%$ of the energy in the reservoir, is subdivided into the various individual modes of the molecules. Carbon dioxide has three separate modes and contributes the bulk of the vibrational energy. The bending mode of the carbon dioxide molecule at a wave number of $667 \mathrm{~cm}^{-1}$ is doubly degenerate and contributes the most energy in the equilibrium reservoir. Carbon monoxide and diatomic oxygen have one mode each, but contribute only a very small amount to the total.

For the nominal freestream conditions that were obtained from the nozzle code in the previous section, the

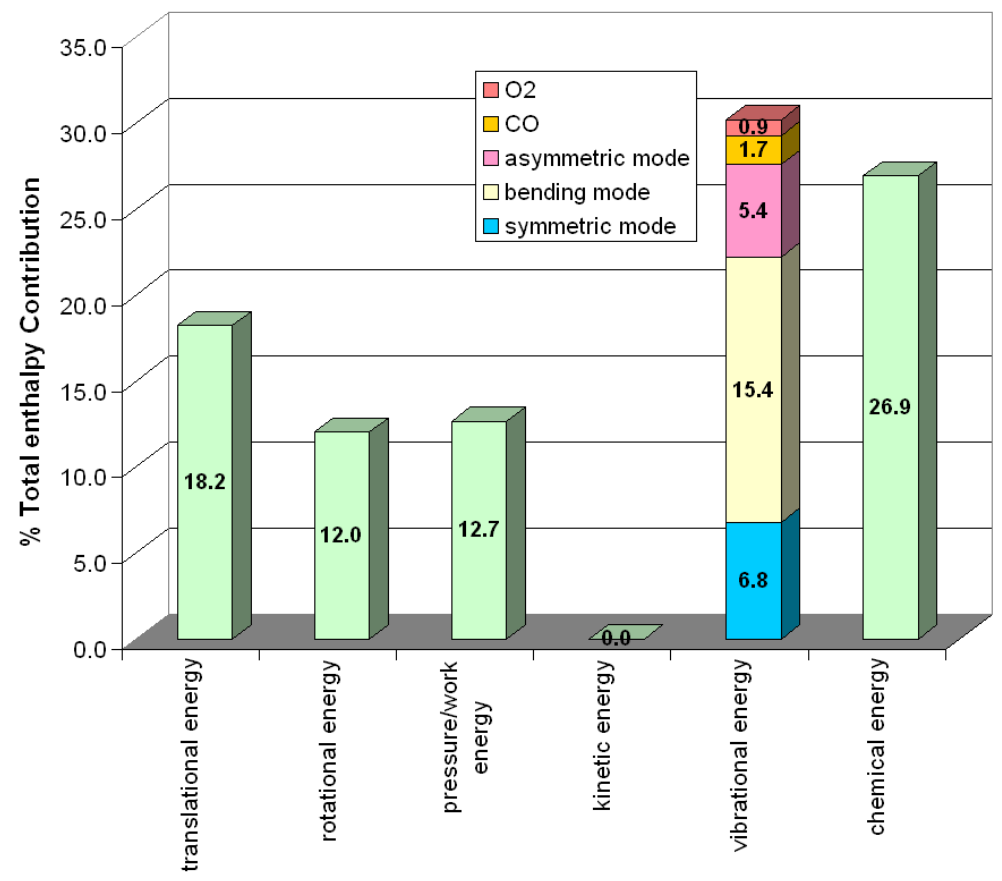

Figure 7. Distribution of Energy Modes for the Reservoir Conditions Computed for Run 8 
vibrational energy was found to have relaxed to $3.6 \%$ of the total increase (an equilibrium level) and the chemical energy was found to have relaxed to $15.4 \%$ of the enthalpy. Thus, approximately two-thirds of the energy in these modes in the reservoir was reclaimed by the translation, rotation, and kinetic modes of the gas. Carbon dioxide is known to have additional thermodynamic complexities, however, particularly when it is expanded from a high temperature reservoir. In fact, $\mathrm{CO}_{2}$ is one of the more common mediums used in gasdynamic lasers ${ }^{32}$. Power extraction in a $10.6 \mu \mathrm{m}$ gasdynamic laser occurs because the asymmetric stretching mode of $\mathrm{CO}_{2}$ relaxes very much slower than the other two modes, and this effect has been shown to occur even at very high reservoir pressures on the order of this run ${ }^{33}$. Per Fig. 7, even a complete freezing of this mode at the reservoir energy level can account for only $5.4 \%$ of the total enthalpy of the flow. The energy distribution shows that the total sum of the vibrational and chemical enthalpy increase of the test gas is $57.1 \%$ of the total flow enthalpy. This value is significantly higher than the fraction we find in testing air. Thus, we presume that a more complex relaxation process may be occurring in the nozzle that incorporates more than just the energy from the asymmetric stretching mode. In particular, the coupling of the chemical recombination to the $\mathrm{V}-\mathrm{V}$ and $\mathrm{V}-\mathrm{T}$ exchange processes seems an open question for this flow. Carbon monoxide is also used as a reactant in gasdynamic lasers principally because it can undergo population inversion by pumping the molecules into the upper quantum levels as a result of anharmonic vibrational behavior. Thus, the combined interaction between population inversion of the molecules, V-V exchange, V-T exchange, and vibration-dissociation coupling suggests that there may be significant uncertainty in the way that the flow is calculated.

As a first approximation to understand the sensitivities to the thermochemical modeling of the expansion process, we have used the measured shock stand-off distance at the stagnation point of the model as a metric with which to understand the accuracy of the flow conditions. Since the exact mechanisms with which this energy exchange and freezing process occur in the nozzle are not understood, we have taken the most straight-forward approach by defining specified amounts of frozen vibrational or chemical energy in the test section of the facility and testing the effects of this on the flowfield of the model. Because the program tested a blunt body where the flowfield is dominated by a strong bow shock, the flow is quickly equilibrated behind the shock, no matter what the state of the flow in the freestream. The freestream conditions that were computed using the nozzle code for the nominal case as given in Table 2 were used as a basis for defining several arbitrary variations. Because Pitot pressure probes and the surface pressure gages on the sphere-cone model are in relatively good agreement with the predictions, the same dynamic pressure of the freestream was preserved in all modified cases. Because total enthalpy of the flow was computed from the incident and reflected shock calculations in the shocktube and because the surface heating of the model is in relatively good agreement with the prediction of a fully-catalytic wall, the total enthalpy was held the same in all cases. Finally, since the Mach number is a function of the effective area ratio of the nozzle, the frozen Mach number has been held the same for all cases. It is known that Mach number does vary somewhat with the real-gas behavior of the expanding flow, but it is believed that this approximation is sufficient for the first-order analysis performed here. These three parameters completely determine the freestream for a specified value of vibrational or chemical energy.

$$
\begin{gathered}
\% v i b=\frac{\left(e_{V I B}-e_{V I B}^{E Q}\right)}{h_{0}^{E F F}} \\
\% \text { chem }=\frac{\left(e_{C H E M}-h_{C O 2}^{f}\right)}{h_{0}^{E F F}}
\end{gathered}
$$

For this analysis, the percent of non-equilibrium vibration is defined as given in Eqn (2). The percent of chemical energy is defined in Eqn (3). Both of these definitions are zero if the flow is in complete equilibrium as in a flight case. Additional frozen energy in the freestream, whether it is chemical or vibrational, while maintaining an approximately equilibrium flow behind the shock has the tendency to push the shock farther outward from the body. This is caused by a change in the density ratio maintained across the shock ${ }^{34}$.

For all cases, a 512x172 axisymmetric grid was employed to maintain consistency between the solutions. In each case, the grid was adapted to the shock layer to generate a quality heating profile and a cell Reynolds number of 1.0 was enforced at the surface ${ }^{35}$. Chemical or vibrational freezing in increments of $10 \%$ were independently considered up to $50 \%$. In the case of chemical freezing, the required amount of chemical energy for the state was simulated by breaking $\mathrm{CO}_{2}$ into $\mathrm{CO}$ and $\mathrm{O}_{2}$ molecules. Either atomic or diatomic oxygen must be present to maintain elemental conservation of the test gas, but the analysis of the nominal condition for this run (and indeed all other runs we have studied) has indicated that there is no atomic oxygen in the test section. Thus, only the chemical breakup into diatomic oxygen has been considered here, although the effect of the atomic versus diatomic oxygen on the shock standoff distance would be an interesting future study. Although we suspect that the actual vibrational 
state of the gas may be highly complex, the required vibrational energy for the vibrational freezing studies has been simulated by calculating the equivalent single degree of freedom vibrational temperature. Note at the outset of the analysis that we do not believe that this is the actual thermochemical state of the gas in the freestream, but we have utilized this simple, first-order method of accounting for the energy to facilitate an understanding of the effects of freezing on the shock stand-off distance.

The resulting impact on the shock standoff at the stagnation point is shown in Fig. 8 which shows the shock standoff distance normalized by the model radius. For this figure, an equilibrium condition was computed, where the gas was $100 \%$ $\mathrm{CO}_{2}$ in the freestream with the vibrational energy fully accommodated to the translation. Then, in separate studies, either the vibrational energy or

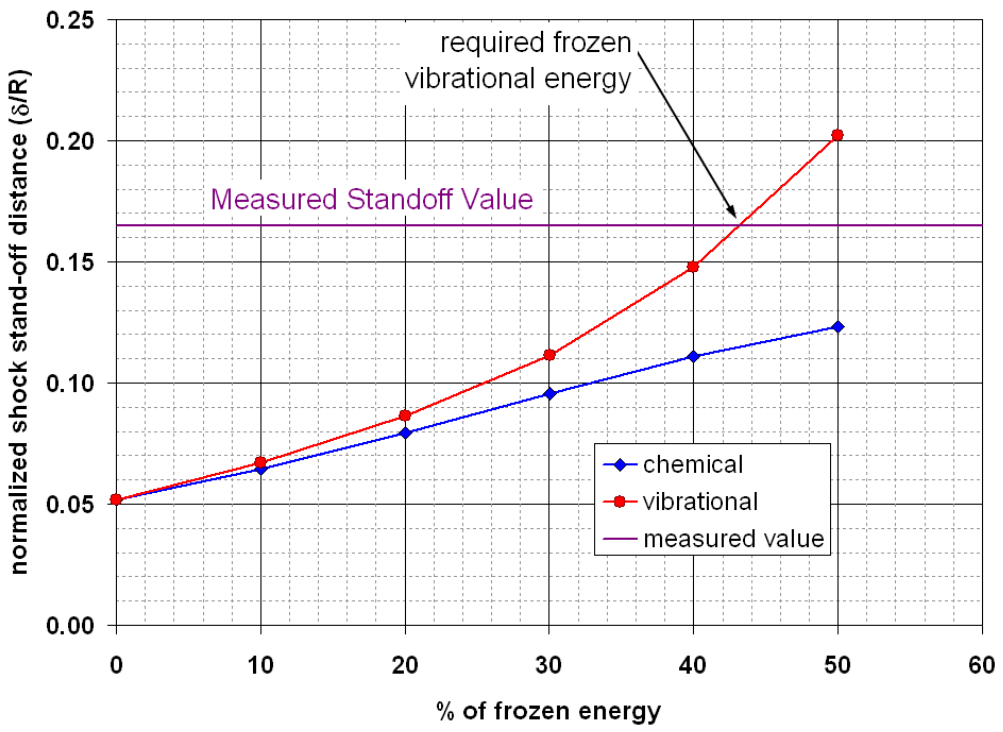

Figure 8. Normalized Standoff Distance of the Shock at the Stagnation Point as a Function of Frozen Freestream Energy Percentage for Run 8 the chemical energy was frozen in $10 \%$ increments up to $50 \%$. The effect of this freezing on the standoff distance is dramatic. The standoff distance found from the nominal case (Fig. 6) is not shown on this graph, but is consistent with the cases in Fig. 8 based on the fraction of dissociated species in Table 2. The most interesting finding from Fig. 8 is that the vibrational energy plays a much more significant role in the standoff increase than chemical dissociation does. This is caused by the fact that the chemical non-equilibrium takes a short time to fully equilibrate behind the bow shock while the vibrational energy equilibrates essentially instantaneously. In fact, a frozen vibrational energy of just greater than $42 \%$ of the total energy increase will match the standoff distance that was measured via the Schlieren photograph. While this is a very large level of frozen energy, referring back to Fig. 7 shows that it is still significantly below the $57.1 \%$ ceiling defined by the combined vibration and chemistry modes in the reservoir. In reality, the flow in the test section for this condition is most likely a mix of frozen vibrational and

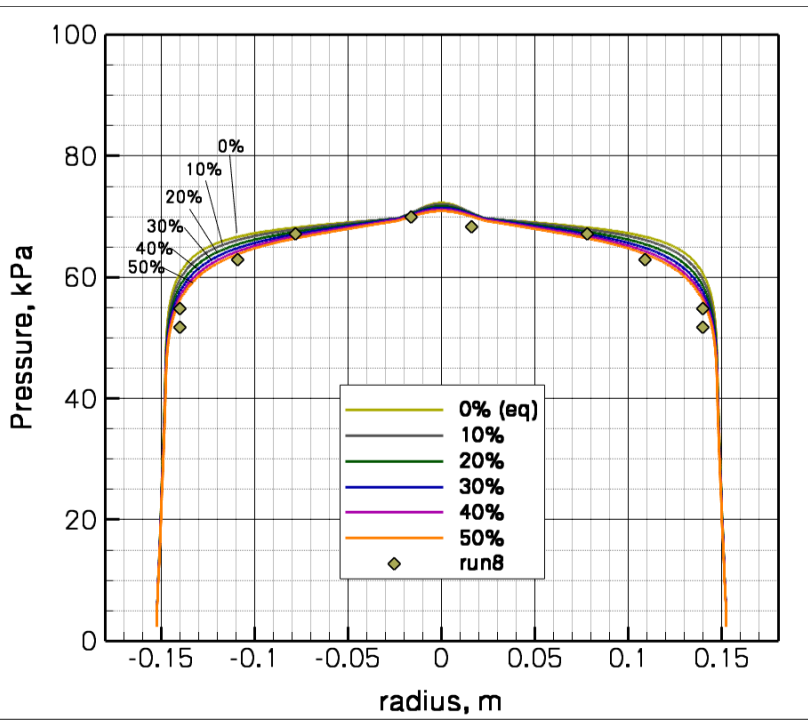

Figure 9. Comparison of Measure Surface Pressure with Predicted Pressures for Specified Levels of Frozen Chemical Energy in the Freestream

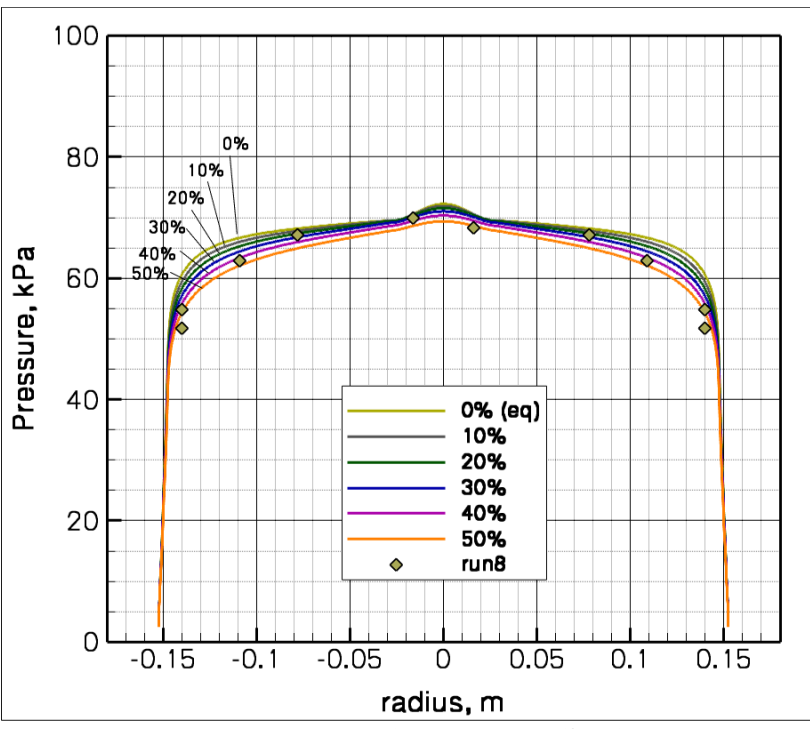

Figure 10. Comparison of Measure Surface Pressure with Predicted Pressures for Specified Levels of Frozen Vibrational Energy in the Freestream 
chemical energy rather than solely one or the other as we have analyzed, but this result does favor the idea that efficient V-T exchange is prevented by the distribution of the vibrational states as recombination occurs. This crude analysis does not provide any evidence of the exact kinetic state of the gas however and much more sophisticated analysis techniques are required to know more.

Figure 9 shows the impact of the chemical study on the pressure measurements and Fig. 10 shows the impact of the vibrational study on the pressure measurements. Although the agreement with the pressure data using the nominal conditions (shown in Fig. 4) might be called "good," a more careful look at Figs. 9 and 10 does show some additional features that were not previously recognized in the data. In both sets of energy studies, the prediction of surface pressure down the conical frustrum of the body does show subtle variation as the frozen energy is increased. This effect is directly caused by the change in shock shape in front of the body. The measured data nearest to the shoulder of the model does show better agreement with the cases that most closely match the shock shape. While this result is not independent of the shock shape analysis, it is a secondary agreement that the modified freestream conditions do a better job of capturing the experiment. The case of $40 \%$ frozen vibration was found to be the best match to the shock standoff at the nose, and Fig. 10 shows that this is also true of the surface pressure.

The effect of the frozen flow condition studies on the surface heat transfer also shows an interesting additional effect. The solutions for a fully catalytic recombination to carbon dioxide at the wall are shown first, with the chemical study shown in Fig. 11 and the vibrational study shown in Fig. 12. As before, the trend in both sets of cases is qualitatively the same. Previous experience has shown that the fully catalytic wall provides the best comparison with the data, and this is still true. Along the conical frustrum, the various freestream models do not make a significant difference in the heating prediction, with all cases lying close together just above the measured data. However, the heating prediction on the spherical nose segment of the body is significantly impacted by the choice of freestream conditions. The three gages at and on either side of the stagnation point of the model that were initially presumed to be affected by some finite-rate catalytic process may now be reinterpreted differently. Although none of the cases studied predicts a stagnation point heating level as low as the measured data, the variation between an equilibrium heating case and the case of maximum frozen vibrational energy is more than $20 \%$. Given that such a sensitivity to the stagnation point heating exists, the initially observed lack of agreement with fully-catalytic recombination must be reinterpreted to be at least largely caused by the thermodynamic state of

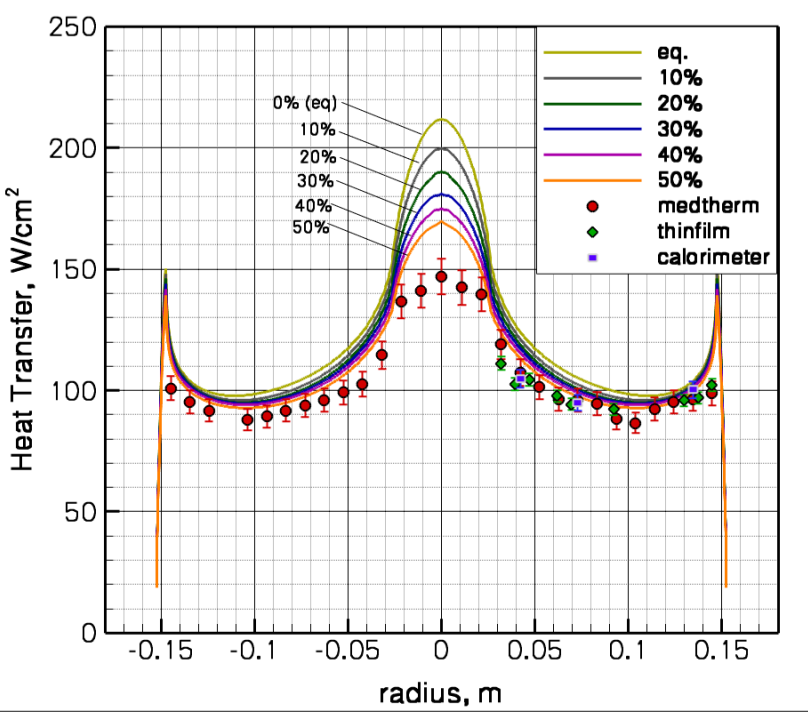

Figure 11. Comparison of Measured Surface Heat Transfer with Fully Catalytic Predictions for Specified Levels of Frozen Chemical Energy in the Freestream

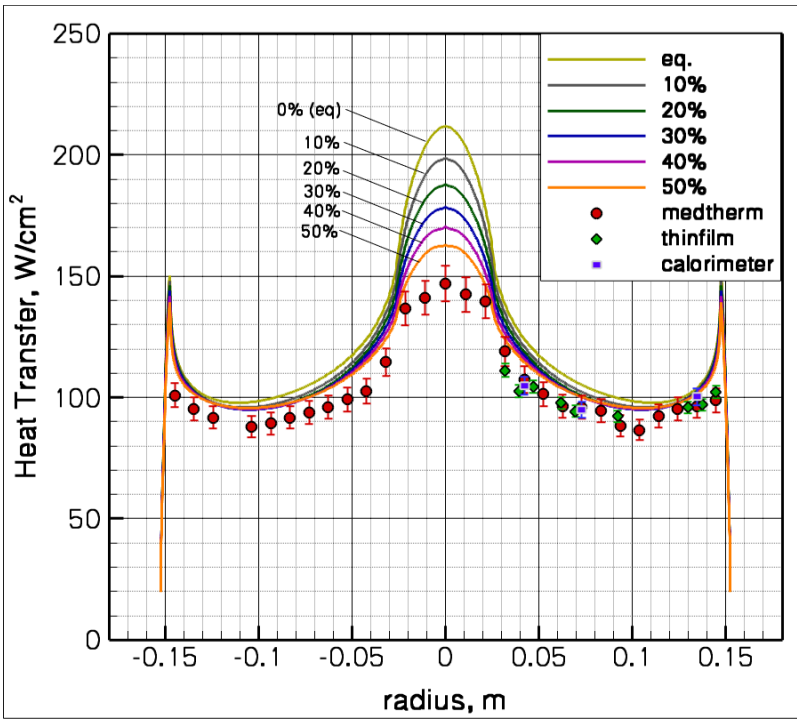

Figure 12. Comparison of Measured Surface Heat Transfer with Fully Catalytic Predictions for Specified Levels of Frozen Vibrational Energy in the Freestream

the freestream test gas.

Although we have seen no evidence that the non-catalytic wall prediction of surface heat transfer can be related to measured test data in the shock tunnel facilities, the set of non-catalytic predictions is shown in Fig. 13 for the chemical study and Fig. 14 for the vibrational study. Here, the trend is similar to the one for the fully-catalytic wall. The heat transfer in the stagnation region is most strongly impacted by the change in the state of the freestream. In the case of the vibrational study, there is virtually no impact on the heating on the conical frustrum as 


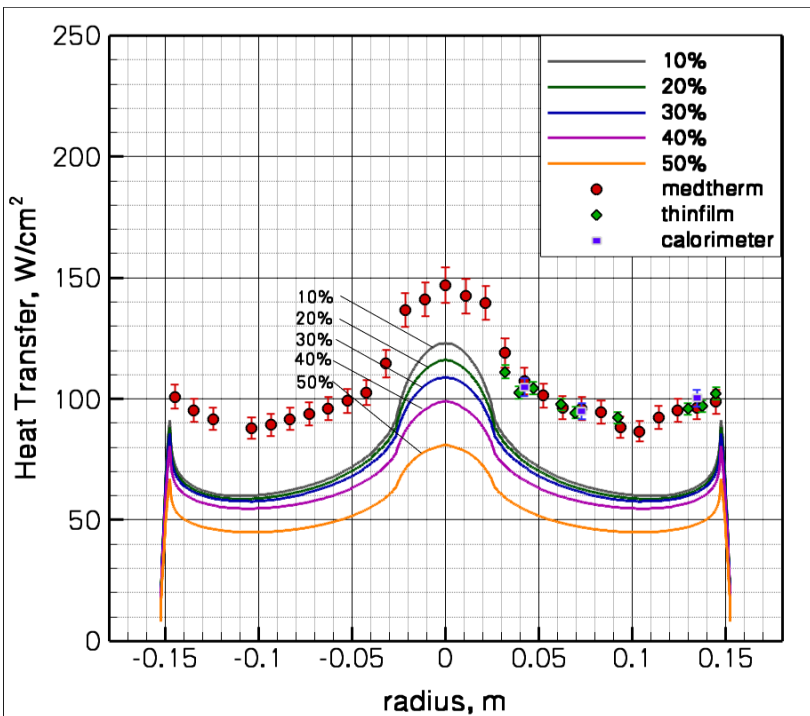

Figure 13. Comparison of Measured Surface Heat Transfer with Non-Catalytic Predictions for Specified Levels of Frozen Chemical Energy in the Freestream

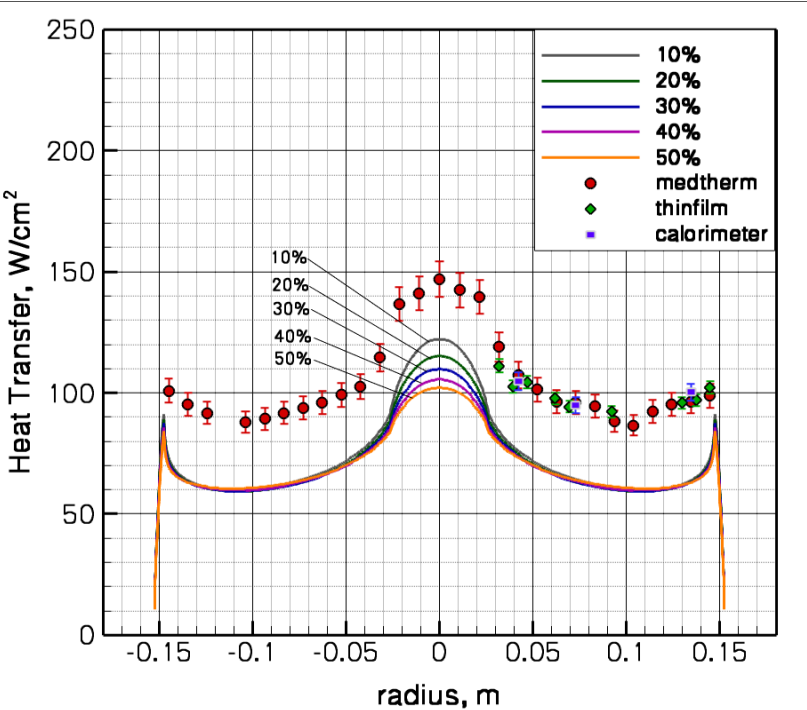

Figure 14. Comparison of Measured Surface Heat Transfer with Non-Catalytic Predictions for Specified Levels of Frozen Chemical Energy in the Freestream

was seen with the fully-accommodated wall cases. The chemical freezing study, however begins to show some effect on the heating for the conical region at very high levels of frozen chemical energy. This is again caused by the finite rate chemical response behind the shock. In the case of the super-catalytic wall, this influence was essentially wiped out by the enforcement of infinite recombination rate at the wall. Here the influence of the chemical rate is slightly more apparent. In no case, however, is the heat transfer calculation for a non-catalytic wall able to predict the level of heating we have measured on this run. Thus, the conclusions that were made based on the nominal conditions still hold - the heating prediction using a non-catalytic wall is not consistent with the evidence obtained from the experiment in the shock tunnel at this enthalpy level.

\section{Impact of Frozen Energy on Transition Behavior}

Given the conclusions from the previous section that the addition of large levels of frozen vibrational or chemical energy in the freestream display significantly improved agreement with the measured surface and flowfield data, the central remaining question is to address the impact that this may have on the transitional behavior of the heating. The main objective of this program was to obtain turbulent heat transfer measurements on the surface of the model and compare the augmented heating in those cases to a laminar baseline or the laminar stagnation point heating of the model.

As a first approximation, we have computed the value of the transition criteria $\mathrm{Re}_{\theta} / \mathrm{M}$ for each of these flowfield cases. The transition stability of this geometry has already been shown to be highly marginal ${ }^{36}$, and it is not clear that the parameter $\mathrm{Re}_{\theta} / \mathrm{M}$ is a valid transition criterion for this flowfield. However, it is hoped that it will provide at least a qualitative insight and that it is consistent with the approximate nature of this entire analysis. It should be noted that run 8 in this program did NOT transition (it remained fully laminar), so the goal of this effort is simply to look at the effect that the altered flow conditions have on $\mathrm{Re}_{\theta} / \mathrm{M}$ to extrapolate to the higher Reynolds number conditions where transitional heating was measured.

The plot of $\mathrm{Re}_{\theta} / \mathrm{M}$ is shown as a function of radial distance in Fig. 15 for the chemical energy study and in Fig. 16 for the vibrational energy study. In both instances, there is some noticeable variation as a function of the amount of frozen energy in the freestream. The computed levels using the nominal set of conditions has also been plotted for reference as this is the analysis method for which transition onset values have already been published. For this axisymmetric sphere-cone, the trend of $\mathrm{Re}_{\theta} / \mathrm{M}$ is the same in all cases and the peak value occurs in nominally the same radial station on the body. The variation in the peak $\mathrm{Re}_{\theta} / \mathrm{M}$ value is approximately $15 \%$ when considering all cases. Based on the conclusions from the previous section that the case with $40 \%$ frozen vibrational energy is the best representative of the actual flowfield for run 8 , the difference in peak $R_{\theta} / \mathrm{M}$ from the nominal case is $8.7 \%$. While significant enough to consider during the analysis of the data, this level of variation is small 


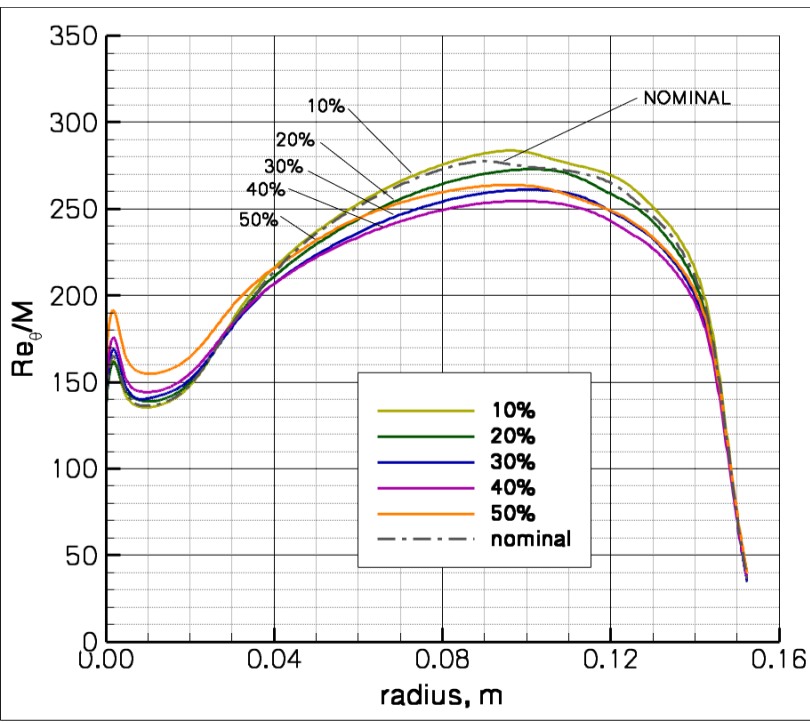

Figure 15. Comparison of Predicted $\mathrm{Re}_{\theta} / \mathrm{M}$ Levels for Various Levels of Frozen Freestream Chemical Energy

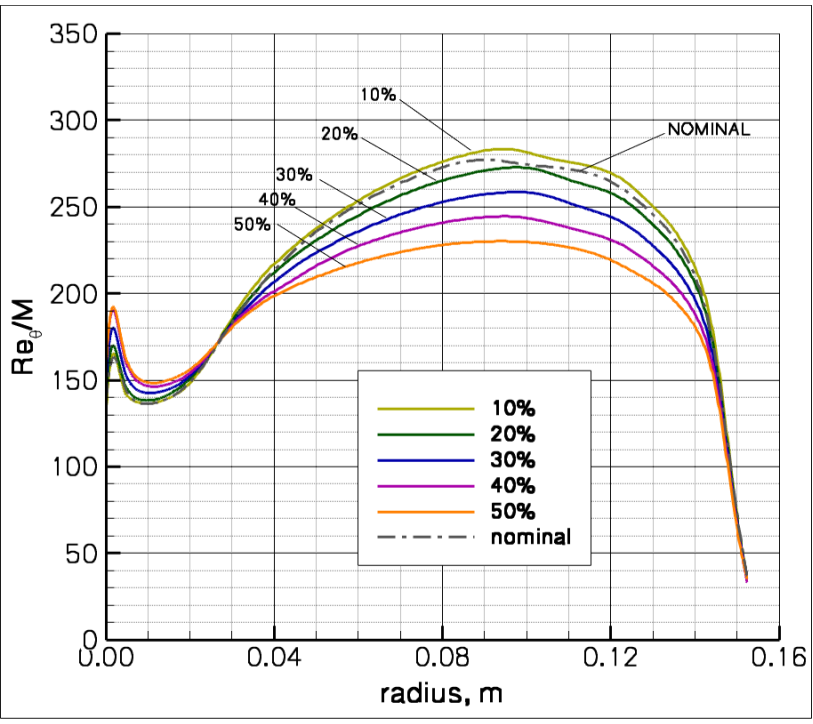

Figure 16. Comparison of Predicted $\mathrm{Re}_{\theta} / \mathrm{M}$ Levels for Various Levels of Frozen Freestream Vibrational Energy

when considering uncertainties in determining $\mathrm{Re}_{\theta} / \mathrm{M}$ transition criteria from the phase one test series. For example, Fig. 16 of Ref. 2 shows significantly larger overall uncertainty bounds of as much as $100 \%$ from some tests, particularly in the $\mathrm{T} 5$ facility where fewer gage locations were monitored.

Thus, the main conclusion from these figures is that one may expect an uncertainty in the $\mathrm{Re}_{\theta} / \mathrm{M}$ prediction of transition onset on the order of $10 \%$ by using the nominal freestream conditions and neglecting the potentially large frozen energy in the freestream of the facility. While important, this uncertainty is well-captured in the overall uncertainty of the transition onset computation. Thus, we are not undermining our understanding of the turbulent heating by our limited knowledge of the freestream. Additionally, the fact that the freezing of energy in the freestream results in a lower laminar stagnation point level means that the ratio of laminar stagnation heating to turbulent frustrum heating will be higher than in flight, providing a built-in conservatism to TPS design.

\section{Conclusions}

The effects of the thermochemical modeling of carbon dioxide have been studied for a typical run in the MSL phase two program in which experimental data was collected in the LENS-I facility on a $70^{\circ}$ sphere-cone model. The measured surface pressure, measured surface heat transfer, and measured Schlieren shock shape have been used as metrics to understand the sensitivity of frozen energy in the freestream flow. Varying levels of frozen chemical energy in the form of carbon monoxide and diatomic oxygen and varying levels of frozen vibrational energy have been studied using our available CFD tools, which consist of a standard five species carbon dioxide chemistry model $\left(\mathrm{CO}_{2}, \mathrm{CO}, \mathrm{O}_{2}, \mathrm{C}, \mathrm{O}\right)$, a simple harmonic oscillator with a single degree of freedom vibrational temperature, and the $T-T_{V}$ vibration-dissociation coupling model. An equilibrium calculation of the reservoir conditions for this run showed that $57.1 \%$ of the total enthalpy of the flow was held in either a vibrational or a chemical degree of freedom.

Analysis of the cases computed showed that frozen energy in the form of chemical dissociation up to $50 \%$ of the total enthalpy did significantly increase the shock standoff distance, but not enough to match the measured value on the stagnation line of the flow from the Schlieren picture. Frozen energy in the form of vibration, however, was found to have a somewhat more significant impact on the solution. A frozen vibrational energy content of approximately $42 \%$ of the total enthalpy of the flow matched not only the shock shape of the Schlieren photograph, but significantly improved the quality of the prediction of both surface pressure and surface heat transfer for this run.

While this first-order analysis of flow sensitivity did yield a set of conditions that improves agreement with all of the measured experimental data, these conditions should not be considered to be the exact freestream conditions of the facility. These authors believe that the thermochemical state of the gas in the freestream may be significantly more complex than this analysis allows for. We have learned that the analysis of $\mathrm{CO}_{2}$ undergoing such a strong expansion as in the LENS-I facility will involve large levels of chemical and vibrational energy that include the need 
to better understand intramolecular V-V exchange, intermolecular V-V exchange, V-T exchange, state-specific population inversion, vibration-dissociation coupling, and transient catalytic surface reactions. These effects cannot be easily separated in this case, and a better understanding of the combined influence of all of these effects is needed to better understand the freestream state of the gas.

In spite of this difficult problem, we have shown that the uncertainty in the freestream of the test facility amounts to a nominally $10 \%$ uncertainty in the transition onset point of the surface heating based on a simple $\operatorname{Re}_{\theta} / \mathrm{M}$ criterion. This uncertainty is well within the existing bound of the uncertainty in the transitional heating on the MSL flight model. Thus, the data for transition onset and turbulent heating augmentation may be analyzed with the adequate forethought to the thermodynamics of the gas that we have suggested. Additionally, the analysis of the freestream conditions has shown that the surface heating data is best captured with a model including fully-catalytic recombination at the surface of the cold-wall model. The initial conclusion that the nose of the model displayed a finite rate catalytic behavior now suggests that this discrepancy is simply one more artifact of the thermochemical state of the gas in the freestream. This conclusion is completely consistent with the effects of surface catalysis that we have seen in air and nitrogen at $5 \mathrm{MJ} / \mathrm{kg}$ enthalpy levels.

The study of laminar and turbulent heating on a sphere-cone with carbon dioxide in the Caltech $\mathrm{T} 5$ facility did not show obvious evidence of the level of frozen energy that we have seen in LENS. We believe that this is due to the significantly lower Mach number that the tests in T5 were run at. The tests in the LENS facility were made with the D-nozzle that has a geometric area ratio of nearly 1000:1, and it is this large amount of expansion of the gas that seems to have created such a complex state of the gas. Our main conclusion from this study is that the thermochemical complexities that arose in the testing in carbon dioxide in a reflected shock tunnel could be avoided by using the LENS-X expansion tunnel. Because the expansion tunnel does not stagnate the gas before expanding it to the test section, the flow would be free of these thermodynamic effects and the uncertainties caused by them. Thus, a future program to study aerothermal effects of Martian entry would also make use of the expansion tunnel in addition or instead of a reflected shock tunnel to significantly enhance our understanding of the data.

\section{Acknowledgements}

Thank you to Dr. Graham Candler for reviewing this publication and providing feedback and discussion.

\section{References}

${ }^{1}$ MacLean, M.; Wadhams, T.; Holden, M.; and Hollis, B. "Investigation of Blunt Bodies with $\mathrm{CO}_{2}$ Test Gas including Catalytic Effects”. AIAA Paper 2005 - 4693. 38 ${ }^{\mathrm{TH}}$ AIAA Thermophysics Conference, Toronto, CA: 6 - 9 June 2005.

${ }^{2}$ Hollis, B.R.; Liechty, D.S.; Wright, M.W.; Holden, M.S.; Wadhams, T.P.; MacLean, M.; and Dyakonov, A. "Transition Onset and Turbulent Heating Measurements for the Mars Science Laboratory Entry Vehicle”. AIAA Paper 2005-1437. 43 ${ }^{\mathrm{RD}}$ Aerospace Sciences Meeting \& Exhibit. Reno, NV: 10-14 January 2005.

${ }^{3}$ Wright, M.J.; Olejniczak, J.; Brown, J.L; Hornung, H.G.; and Edquist, K.T. “Computational Modeling of T5 Laminar and Turbulent Heating Data on Blunt Cones, Part 2: Mars Applications”. AIAA Paper 2005-0177. 43 ${ }^{\mathrm{RD}}$ Aerospace Sciences Meeting \& Exhibit. Reno, NV: 10-14 January 2005.

${ }^{4}$ Lu, F.K. and Marren, D.E. Eds. Advanced Hypersonic Test Facilities. AIAA Progress in Astronautics and Aeronautics Series: Vol 198. Chapter 4. Reston, VA: American Institute of Aeronautics and Astronautics, 2002.

${ }^{5}$ Holden, M.S.; Wadhams, T.P.; and Candler, G.V. "Experimental Studies in the LENS Shock Tunnel and Expansion Tunnel to Examine Real-Gas Effects in Hypervelocity Flows”. AIAA Paper 2004-0916. January 2004.

${ }^{6}$ Parker, R.; Wakeman, T.; Holden, M.; and MacLean, M. "Measuring NO Freestream Concentration Using Quantum Cascade Lasers at CUBRC”. AIAA Paper 2006-0926. $44^{\mathrm{TH}}$ Aerospace Sciences Meeting \& Exhibit. Reno, NV: 9-12 January 2006.

${ }^{7}$ MacLean, M.; Candler, G.; and Holden, M. "Numerical Evaluation of Flow Conditions in the LENS Reflected ShockTunnel Facilities”. AIAA Paper 2005-0903. 43 ${ }^{\mathrm{RD}}$ Aerospace Sciences Meeting \& Exhibit. Reno, NV: 10-14 January 2005.

${ }^{8}$ Spencer, David; Blanchard, Robert; Thurman, Sam; Braun, Robert; Peng, Chia-Yen; and Kallemeyn, Pieter. "Mars Pathfinder Atmospheric Entry reconstruction”. AAS 98-146. AAS/AIAA Space Flight Mechanics Meeting, Monteray, CA. 9-11 February 1998.

${ }^{9}$ Wright, M.J.; Bose, D.; and Candler, G.V. “A Data Parallel Line Relaxation Method for the Navier-Stokes Equations”. AIAA Journal. Vol 36, no 9. Pgs 1603 - 1609. Sept 1998.

${ }^{10}$ MacCormack, R.W. and Candler, G.V. "The Solution of the Navier-Stokes Equations Using Gauss-Seidel Line Relaxation”. Computers and Fluids. Vol 17, No 1. Pgs 135 - 150. 1989.

${ }^{11}$ Candler, G.V. “Chemistry of External Flows”. Aerothermochemistry for Hypersonic Technology: Von Karman Institute for Fluid Dynamics Lecture Series. VKI LS 1995-04.

${ }^{12}$ Landau, L. and Teller, E. “Theory of Sound Dispersion”. Physikalische Zeitschrift der Sowjetunion. Vol 10, no 34. 1936.

${ }^{13}$ Millikan, R. and White, D. "Systematics of Vibrational Relaxation”. Journal of Chemical Physics. Vol 39, no 12. Pgs 3209 - 3213. 1963. 
${ }^{14}$ Camac, M. “CO 2 Relaxation Processes in Shock Waves”. Fundamental Phenomena in Hypersonic Flow. J.G. Hall Ed. Cornell University Press. Pgs 195 - 215, 1964.

${ }^{15}$ Park, C.; Howe, J.T.; Jaffe, R.J.; and Candler, G.V. "Review of Chemical-Kinetic Problems of Future NASA Missions II: Mars Entries”. Journal of Thermophysics and Heat Transfer. Vol 8, no 1. Pgs 9 - 23. 1994.

${ }^{16}$ Park, Chul. "Assessment of Two-temperature Kinetic Model for Ionizing Air”. AIAA Paper 87-1574. AIAA 22 ${ }^{\text {ND }}$ Thermophysics Conference. Honolulu, HI: 8-10 June 1987.

${ }^{17}$ Palmer, G.E. and Wright, M.J. “A Comparison of Methods to Compute High Temperature Gas Viscosity”. Journal of Thermophysics and Heat Transfer. Vol 17, no 2. Pgs 232 - 239. 2003.

${ }^{18}$ Palmer, G.E. and Wright, M.J. “A Comparison of Methods to Compute High Temperature Gas Thermal Conductivity”. AIAA Paper 2003-3913. Jun 2003.

${ }^{19}$ Gupta, R.; Yos, J.; Thompson, R.; and Lee, K. “A Review of Reaction Rates and Thermodynamic and Transport Properties for an 11-Species Air Model for Chemical and Thermal Nonequilibrium Calculations to 30000 K”. NASA RP-1232. August 1990.

${ }^{20}$ Ramshaw, J.D. “Self-consistent Effective Binary Diffusion in Multicomponent Gas Mixtures”. Journal of Non-Equilibrium Thermodynamics. Vol 15, no 3. Pgs 295 - 300. 1990.

${ }^{21}$ Baldwin, B.S. and Lomax, H. “Thin Layer Approximation and Algebraic Model for Separated Turbulent Flows”. AIAA Paper 78-0257. Huntsville, AL: 1978.

${ }^{22}$ Spalart, P.R. and Allmaras S.R. “A One-Equation Turbulence Model for Aerodynamic Flows”. AIAA Paper 92-0439. 30 ${ }^{\mathrm{TH}}$ Aerospace Sciences Meeting \& Exhibit. Reno, NV: 6-9 Jan, 1992.

${ }^{23}$ Menter, F.R. “Two-Equation Eddy-Viscosity Turbulence Models for Engineering Applications”. AIAA Journal. Vol 32, no 8. Pgs $1598-1605$. August 1994.

${ }^{24}$ Brown, James. “Turbulence Model Validation for Hypersonic Flow”. AIAA Paper 2002-3308. ${ }^{\mathrm{TH}}$ Thermophysics and Heat Transfer Conference. St. Paul, MN: 24 - 26 Jun 2002.

${ }^{25}$ Catris S. and Aupoix B. “Improved Turbulence Models for Compressible Boundary Layers.” AIAA Paper 98-2696. $2^{\mathrm{ND}}$ Theoretical Fluid Mechanics Meeting: Albuquerque, NM, June 1998.

${ }^{26}$ Gaydon, A.G. and Hurle, I.R. The Shock Tube in High-Temperature Chemical Physics. New York: Reinhold Publishing Co., 1963.

${ }^{27}$ Lordi, J.A. and Mates, R.E. “Non-equilibrium Expansions of High-Enthalpy Airflows.” Cornell Aeronautical Laboratory Report, ARL 64-206. November 1964.

${ }^{28}$ McIntosh, M. "Computer Program for the Numerical Calculation of Frozen and Equilibrium Conditions in Shock Tunnels". Ph.D. Thesis, Australian National University, 1971.

${ }^{29}$ McBride, B. and Gordon, S. "Computer Program for Calculation of Complex Chemical Equilibrium Compositions and Applications, Part II Users Manual and Program Description”. NASA RP-1311(P2). June 1996.

${ }^{30}$ Candler, Graham V. "Hypersonic Nozzle Analysis Using an Excluded Volume Equation of State”. AIAA Paper 2005 5202. 38 ${ }^{\mathrm{TH}}$ AIAA Thermophysics Conference, Toronto, CA: 6 - 9 June 2005.

${ }^{31}$ MacLean, M. and Holden, M. "Catalytic effects on Heat transfer Measurements for Aerothermal Studies with CO2”. AIAA Paper 2005-0182. 44 ${ }^{\mathrm{RD}}$ Aerospace Sciences Meeting \& Exhibit. Reno, NV: 9-12 January 2006.

${ }^{32}$ Anderson, John D. Gasdynamic Lasers: An Introduction. New York: Academic Press, 1976.

${ }^{33}$ Makarov, V.N. and Losev, S.A. "Gasdynamic Laser Power at High Pressure”. Journal of Applied Mechanics and Technical Physics, Vol 16, No 4. Pgs 483 - 486. Springer New York, July 1975.

${ }^{34}$ Park, C. Nonequilibrium Hypersonic Aerothermodynamics. New York: Wiley, 1990.

${ }^{35}$ Papadopoulos, P.; Venkatapathy, E.; Pradhu, D.; Loomis, M.; and Olynick, D. "Current Grid-generation Strategies and Future Requirements in Hypersonic Vehicle Design, Analysis and Testing”. Applied Mathematical Modeling, Vol 23. Pgs 705 735. 1999.

${ }^{36}$ Johnson, H.; Candler, G.; and Wright, M. "Boundary Layer Stability Analysis of Mars Science Laboratory Aeroshell”. AIAA Paper 2005-0920. 44 ${ }^{\mathrm{RD}}$ Aerospace Sciences Meeting \& Exhibit. Reno, NV: 9-12 January 2006. 